\title{
COMPARAÇÃO ENTRE MÉTODOS PARA A AVALIAÇÃO DO VIGOR DE LOTES DE SEMENTES DE COUVE-BRÓCOLOS (Brassica oleracea L. var. italica PLENK) ${ }^{1}$
}

\author{
CIBELE CHALITA MARTINS², ADRIANA MARTINELLI-SENEME ${ }^{3}$, MARCIA MARIA CASTRO ${ }^{4}$, \\ JOÃO NAKAGAWA², CLÁUDIO CAVARIANI ${ }^{2}$
}

\begin{abstract}
RESUMO - Os testes de vigor e o teste de germinação são componentes essenciais no controle de qualidade das empresas de produção de sementes. Com o objetivo de verificar a eficiência de diferentes testes de vigor e de variações de suas metodologias na avaliação da qualidade de sementes de couve-brócolos visando diferenciação de lotes e previsão de emergência em bandeja, cinco lotes de sementes do híbrido Flórida foram submetidos aos seguintes testes: germinação; primeira contagem de germinação; emissão de raiz primária (após 48, 56, 72, 80 e 96 h após a instalação do teste de germinação); emergência de plântulas em substrato; envelhecimento acelerado com água ( $1 \mathrm{~g}$ de sementes mantidas a $41^{\circ} \mathrm{C}$ por 48 e $72 \mathrm{~h}$ a $100 \%$ UR); envelhecimento acelerado com solução saturada de sal (mesmo procedimento do item anterior, porém usando solução de $\mathrm{NaCl}$, $40 \%$ e $76 \%$ UR); condutividade elétrica ( 50 sementes em $25 \mathrm{~mL}$ de água destilada a $25^{\circ} \mathrm{C}$ e leituras após 2, 4, 6, 8 e $24 \mathrm{~h}$ ). Todos os testes apresentaram correlação significativa com a porcentagem de emergência de plântulas em substrato, a $1 \%$ de probabilidade. Os testes de envelhecimento acelerado com solução saturada de sal por $48 \mathrm{~h}$ e de condutividade elétrica após 8 e 24 h de embebição foram eficientes e tiveram resultados semelhantes aos da emergência em substrato. Os testes da primeira contagem de germinação, emissão da raiz primária após $56 \mathrm{~h}$ e envelhecimento acelerado com solução saturada de sal por $72 \mathrm{~h}$, apresentaram-se mais eficientes que a emergência de plântulas em substrato na diferenciação do vigor dos lotes.

Termos para indexação: controle de qualidade, condutividade elétrica, envelhecimento acelerado, olerícolas.
\end{abstract}

\section{METHODS OF COMPARISON TO EVALUATE BROCCOLI SEED LOT VIGOR}

\begin{abstract}
The vigor tests and germination test are essential components of seed quality control to the seed industry. This research was understaken to study an adequate method to estimate vigor in different seed lots and to predict seedling emergence on spedling trays. Five lots of broccoli 'Florida' hybrid seeds were submitted to the following tests: germination; first germination count; primary root emission (48, 56, 72, 80, and 96 hour after sowing); seedling emergence on spedling trays; accelerated aging with water $\left(1 \mathrm{~g}\right.$ of seeds maintained at $41^{\circ} \mathrm{C}$ during 48 and 72 hours); accelerated aging with salt (the same procedure of last item, but using $40 \% \mathrm{NaCl}$ solution); electrical conductivity (50 seeds in $25 \mathrm{~mL}$ of distilled water at $25^{\circ} \mathrm{C}$ and evaluations after 2, 4, 6, 8, and 24 hours imbibition). All the tests presented significant correlation with emergence on spedling trays at $1 \%$ probability level. The accelerated aging tests with saturated salt solution during 48 hours and the electrical conductivity after 8 and 24 hours imbibitions showed similar results at emergence on spedling trays. The first germination count, primary root emission after 56 hours and accelerated aging with salt during 72 hours were more efficient than emergence on spedling trays to differentiate vigor among seed lots.
\end{abstract}

Index terms: quality control, electrical conductivity, accelerated aging, vegetable.

\footnotetext{
${ }^{1}$ Aceito para publicação em 13.12.2002.

2 Prof. Dr., Depto. Produção Vegetal, FCA/UNESP; Cx. Postal 237, $18603-$ 970, Botucatu-SP, Brasil; e-mail: cibele@fca.unesp.br

${ }^{3}$ Prof. Dr., Curso de Engenharia Agrícola, Faculdades Integradas
}

\footnotetext{
"Espírita"; R. Tobias de Macedo Júnior 333, 82010-340, Curiritba-PR, Brasil; e-mail: adrianaseneme@bol.com.br

${ }^{4}$ Eng $^{\mathrm{a}}$ Agr ${ }^{\mathrm{a}}$, Mestre, aluna de Pós-Graduação do Depto. de Produção Vegetal, nível de doutorado, Faculdade de Ciências Agronômicas da UNESP de Botucatu, SP; e-mail: marciacastro@fca.unesp.br
} 


\section{INTRODUÇÃO}

A qualidade fisiológica das sementes é rotineiramente avaliada pelo teste de germinação, porém esse teste fornece condições favoráveis ao processo, o que possibilita que o lote expresse sua máxima germinação nessa condição. Os testes de vigor permitem identificar os lotes com maior ou menor probabilidade de apresentar melhor desempenho no campo ou durante o armazenamento. Esse tipo de informação, pode ajudar na tomada de decisões internas das empresas produtoras de sementes quanto ao destino de determinado lote, quanto à região de comercialização ou à conveniência de armazenálo ou vendê-lo num curto espaço de tempo. Assim, esses testes são componentes essenciais de um programa de controle de qualidade de sementes (Krzyzanowski et al., 1999). A avaliação do vigor de sementes, como rotina pela indústria sementeira, tem evoluído à medida que os testes disponíveis vêm sendo aperfeiçoados, permitindo a obtenção de resultados consistentes e reproduzíveis.

Alguns testes de vigor podem ser realizados conjuntamente com o teste de germinação. Dentre eles a primeira contagem de germinação, realizada para facilitar a condução do teste de germinação, pode ser considerada um teste de vigor, pois sabe-se que no processo de deterioração a velocidade da germinação é um dos primeiros parâmetros a ser afetado. Utilizando-se o mesmo princípio, pode-se avaliar o vigor de um lote pela precocidade da emissão da raiz primária, com grande eficiência, como foi observado por Salgado (1996) em sementes de milho. $\mathrm{O}$ aspecto positivo desses testes seria a economia, praticidade e simplicidade.

Outro teste indicado para avaliar o vigor é o de condutividade elétrica. Este avalia indiretamente a concentração de eletrólitos liberados pelas sementes durante a embebição, fornecendo resultados no prazo máximo de 24 horas, sendo, portanto, um teste rápido. Pesquisas realizadas com sementes de olerícolas, como feijão-de-vagem, quiabo (Dias et. al., 1998) e pimentão (Panobianco \& Marcos-Filho, 1998; Torres \& Minami, 1999) têm demonstrado que o decréscimo na germinação e no vigor é diretamente proporcional ao aumento da concentração de eletrólitos liberados pelas sementes durante a embebição. Em trabalhos com sementes pequenas, como olerícolas, o período de embebição pode ser bem menor do que o utilizado para cereais e leguminosas (24 horas). Espécies como aipo, alface, aneto e cenoura apresentaram $90 \%$ da lixiviação de potássio num período de 5 a 15 minutos, enquanto em colza, ervilha e girassol, isso ocorre entre 14 e 16 horas (Simon \& Mathavan, 1986). Dias et al. (1998) verificaram que a embebição por 4 horas foi suficiente na identificação de diferenças entre lotes de sementes de quiabo, enquanto para feijão vagem (Dias et al., 1998) e couvebrócolos (Mello et al., 1999) resultados mais precisos foram obtidos, apenas, após 24 horas. Para sementes de tomate, o tempo de embebição para o teste da condutividade elétrica pode variar de quatro (Sá, 1999) a seis horas (Rodo et al., 1998) e a eficiência da metodologia do teste pode depender da cultivar a ser avaliada (Rodo et al., 1998).

Um dos testes mais utilizados para a avaliação do vigor é o envelhecimento acelerado (Vieira \& Carvalho, 1994), que se baseia no aumento da deterioração das sementes, quando expostas a condições adversas de alta temperatura e umidade relativa. Sob essas condições, sementes de baixa qualidade deterioram-se mais rapidamente do que sementes mais vigorosas, estabelecendo diferenças no potencial fisiológico das amostras avaliadas. Ensaios de aprimoramento da metodologia do envelhecimento acelerado para olerícolas têm sido implementados, testando-se diferentes temperaturas e tempos de exposição das sementes ao estresse e comparando-se os resultados à emergência de plântulas em campo e com outros testes de vigor, obtendo-se as seguintes recomendações: $42^{\circ} \mathrm{C}$ por $72 \mathrm{~h}$ para tomate (Nascimento et al., 1993), alface e cebola (Marcos-Filho, 1999); $42^{\circ} \mathrm{C}$ por $48 \mathrm{~h}$ para couve-brócolos (Mello et al., 1999) e para rabanete (Marcos-Filho, 1999$) ; 41^{\circ} \mathrm{C}$ por $72 \mathrm{~h}$ para tomate, pimenta, canola, cebola (Hampton \& Tekrony, 1995) e melão (Torres, 2002); $45^{\circ} \mathrm{C}$ por 48h para couve-brócolos (Tebaldi et al., 1999). Mais recentemente, grande parte dos pesquisadores que se dedica a estudos sobre esse teste indicam a padronização do uso de $41^{\circ} \mathrm{C}$ (Marcos-Filho, 1999).

Por outro lado, métodos alternativos para o teste de envelhecimento acelerado em espécies de sementes pequenas vêm sendo estudados, como a substituição da água por soluções saturadas de sais. Dependendo da solução utilizada, são obtidos níveis específicos de umidade relativa do ar, permitindo adequar a taxa de absorção de água da semente, a velocidade e a intensidade de deterioração da mesma. Panobianco \& Marcos-Filho (1998), comparando o vigor de lotes de sementes de pimentão e Rodo et al. (1999), em estudo semelhante com sementes de cenoura, observaram que o teste de envelhecimento acelerado $\left(41^{\circ} \mathrm{C}\right.$ por $\left.72 \mathrm{~h}\right)$ com uso de solução saturada de $\mathrm{NaCl}$ foi mais eficiente na detecção de diferenças de qualidade de lotes que o envelhecimento acelerado sem o uso do sal. Esses resultados divergem dos observados por Torres (2002), em avaliação da mesma metodologia para sementes de melão.

Assim, o presente trabalho foi conduzido com o objetivo de verificar a eficiência de diferentes testes de vigor e de 
variações de suas metodologias na avaliação da qualidade de sementes de couve-brócolos visando diferenciação de lotes e previsão de emergência em bandeja.

\section{MATERIAL E MÉTODOS}

O trabalho foi conduzido no Laboratório de Análise de Sementes do Departamento de Produção Vegetal da Faculdade de Ciências Agronômicas da UNESP-Campus de Botucatu, SP. Foram utilizados 5 lotes de couve-brócolos híbrido Flórida colhidos nos seguintes locais e anos: Lotes 1 e 2 - 1996 em Joanópolis/SP; Lotes 3 e 4 - 1995 em Atibaia/SP e Lote 5 1996 em Atibaia/SP que se encontravam armazenados em condições de câmara fria e seca até a realização do estudo em 2000. Foram aplicados os seguintes testes de avaliação de qualidade para cada lote de sementes: germinação - realizado com quatro subamostras de 50 sementes, semeadas sobre duas folhas de papel mata-borrão umedecidas com 2,5 vezes o peso do papel em água, em caixas pláticas transparentes tipo gerbox, em temperaturas alternadas de $20-30^{\circ} \mathrm{C}$ e 8 horas de luz. As contagens das plântulas normais foram efetuadas no quinto e décimo quarto dia (Brasil, 1992); primeira contagem de germinação - realizada conjuntamente com o teste de germinação, contabilizando-se as plântulas normais presentes no quinto dia após a semeadura; precocidade de emissão de raíz primária - realizada contabilizando-se o número de sementes que emitiram raiz primária após 48, 56, 72, 80 e 96 horas da semeadura (contagem diária sempre no início e final do período da temperatura mais alta do teste de germinação); emergência em substrato - utilizando-se quatro repetições de 100 sementes por lote, semeando-se duas sementes por célula em bandejas, a $0,5 \mathrm{~cm}$ de profundidade, em substrato próprio para produção de mudas de olerícolas (Plantmax), umedecidos duas vezes ao dia e conduzido em tunel plástico. Aos 14 dias foi realizada a contagem de plântulas normais emersas. A umidade relativa e temperatura do ambiente durante esse período foi registrada em termohigrômetro; envelhecimento acelerado com água conduzido com $1 \mathrm{~g}$ de sementes sobre tela em caixa plástica tipo gerbox contendo $40 \mathrm{ml}$ de água, mantidas a $41^{\circ} \mathrm{C}$ (100\%UR) por 48 e 72 horas (Hampton \& Tekrony, 1995; Panobianco \& Marcos-Filho, 1998) seguindo-se a avaliação da germinação, utilizando o mesmo procedimento para o teste de germinação com contagem no quinto dia; envelhecimento acelerado com solução saturada de sal - utilizou-se o mesmo procedimento do item anterior, porém a água foi substituída por uma solução saturada de $\mathrm{NaCl}$ (40\%), com o uso do sobrenadante, de modo a obter um ambiente com $76 \%$ de UR, adaptando-se a metodologia utilizada por Jianhua \& McDonald, (1996); Panobianco \& Marcos-Filho (1998) e Rodo et al. (1999); condutividade elétrica - foram utilizadas quatro subamostras de 50 sementes por lote, pesadas em balança com precisão de $0,001 \mathrm{~g}$ e colocadas para embeber em copos plásticos contendo $25 \mathrm{ml}$ de água destilada, a $25^{\circ} \mathrm{C}$, as leituras foram efetuadas após 2, 4, 6, 8 e 24 horas; teor de água das sementes - determinado antes e após o teste de envelhecimento acelerado, tanto o conduzido com água, quanto o com solução saturada de sal, utilizando-se duas subamostras para cada lote e adotando-se o método da estufa a $105 \pm 3^{\circ} \mathrm{C} / 24 \mathrm{~h}$ (Brasil, 1992).

Procedimento estatístico - a análise de variância foi realizada separadamente para cada teste, em delineamento inteiramente casualizado, com quatro repetições, onde a comparação entre as médias dos lotes foi efetuada pelo teste de Tukey, a 5\% de probabilidade. Os dados expressos em porcentagem foram transformados em arc sen $(\mathrm{x} / 100)^{1 / 2}$ e quando ocorreu valor igual a zero, os dados em porcentagem foram transformados em $(x+0,5)^{1 / 2}$. Realizou-se a determinação dos coeficientes de correlação simples entre os resultados dos testes de laboratório e da emergência de plântulas em substrato em bandeja.

\section{RESULTADOS E DISCUSSÃO}

A emergência de plântulas em substrato foi o teste usado como referência na comparação com os demais testes de vigor. Durante o período de condução do teste, o ambiente da estufa plástica apresentou temperatura de $27 \pm 9^{\circ} \mathrm{C}$ e umidade relativa de $68 \pm 29 \%$. Pelos resultados do teste de emergência de plântulas em substrato os lotes foram agrupados em três classes de vigor: alto (lotes 1, 2 e 3), médio (lote 4) e baixo (lote 5). Os testes que apresentaram resultados similares à emergência em substrato foram o de envelhecimento acelerado com sal, por 48 h e o de condutividade elétrica após 8 e 24 horas de embebição, podendo ser apontados como testes de vigor promissores para sementes de couve-brócolos (Tabela 1).

Os testes de germinação e o de condutividade elétrica após 2, 4 e 6 horas, apresentaram-se menos sensíveis que o de emergência de plântulas em substrato, identificando apenas o lote 5 como pior que os demais. Assim, devido a pouca eficiência, esses testes não podem ser indicados para avaliar o vigor das sementes de couve-brócolos, mesmo apresentando correlação significativa com a emergência de plântulas em substrato. $\mathrm{O}$ fato do teste de germinação ser conduzido sob condições ideais, explica a separação dos lotes em ape- 
TABELA 1. Coeficientes de correlação simples (r) entre os resultados dos testes de laboratório e da emergência de plântulas em substrato para mudas, em substrato, para as sementes de cinco lotes de couve-brócolos híbrido Flórida.

\begin{tabular}{|c|c|c|}
\hline \multicolumn{2}{|c|}{ Testes de laboratório $X$ emergência em substrato } & $\mathrm{r}$ \\
\hline Germinação & & $0,962 * * *$ \\
\hline Primeira contagem & & $0,780 * * *$ \\
\hline Emissão de raíz primária & $\begin{array}{l}\text { após } 48 \text { horas } \\
\text { após } 56 \text { horas } \\
\text { após } 72 \text { horas } \\
\text { após } 80 \text { horas } \\
\text { após } 96 \text { horas }\end{array}$ & $\begin{array}{l}0,467 * \\
0,496 * \\
0,675 * * \\
0,702 * * * \\
0,897 * * *\end{array}$ \\
\hline Envelhecimento acelerado com sal & $\begin{array}{l}\text { após } 48 \text { horas } \\
\text { após } 72 \text { horas }\end{array}$ & $\begin{array}{l}0,830 * * * \\
0,831 * * *\end{array}$ \\
\hline Envelhecimento acelerado sem sal & $\begin{array}{l}\text { após } 48 \text { horas } \\
\text { após } 72 \text { horas }\end{array}$ & $\begin{array}{l}0,783 * * * \\
0,778 * * *\end{array}$ \\
\hline Condutividade elétrica & $\begin{array}{l}\text { após } 2 \text { horas } \\
\text { após } 4 \text { horas } \\
\text { após } 6 \text { horas } \\
\text { após } 8 \text { horas } \\
\text { após } 24 \text { horas }\end{array}$ & $\begin{array}{l}-0,816 * * * \\
-0,857 * * * \\
-0,895 * * * \\
-0,919 * * * \\
-0,943 * * *\end{array}$ \\
\hline
\end{tabular}

Significativo a $5 \%(*), 1 \%(* *)$ e $0,1 \%(* * *)$ de probabilidade.

nas duas classes, devido à impossibilidade de detectar pequenas diferenças de vigor.

Os dados obtidos no teste de condutividade elétrica (Tabela 2) demonstraram que o tempo de embebição das sementes pode ser reduzido para 8 horas, sem prejuízos à confiabilidade dos resultados, confirmando informações obtidas em trabalhos com sementes pequenas, como olerícolas, de que o período de embebição pode ser bem menor do que o de 24 horas, utilizado para cereais e leguminosas. (Simon \& Mathavan, 1986; Dias et al. ,1998; Rodo et al., 1998; Sá, 1999). A redução do tempo de obtenção dos resultados do teste de condutividade elétrica é importante pois uma das principais exigências das empresas de sementes tem sido relacionadas à avaliação eficiente e rápida da qualidade das sementes, de modo a permitir a agilização das tomadas de decisões, principalmente no que se refere às operações de colheita, processamento e comercialização.

Os resultados de correlação simples entre condutividade elétrica e os dados de emergência em substrato (Tabela 1) indicaram correlação negativa entre os testes. Isto significa que aumentos nos valores de condutividade elétrica corres- ponderam a queda nos níveis de emergência em substrato (vigor da sementes) e, este fato, concorda com relatos da literatura onde os aumentos nos índices de condutividade elétrica corresponderam a maior lixiviação de solutos e, portanto, à diminuição na qualidade fisiológica das sementes (McDonald \& Wilson, 1979; Powell, 1986 e Marcos-Filho et al., 1990).

Pela Tabela 2, verifica-se que a primeira contagem de germinação, a emissão da raiz primária após 56 horas, e o envelhecimento acelerado com sal por 72 horas, mostraramse mais sensíveis que a emergência de plântulas em substrato, sendo capazes de separar os lotes em quatro classes de vigor (enquanto de emergência em substrato separou em apenas três classes), que também seguiram a ordem decrescente de vigor observada no conjunto dos testes, do lote 1 ao 5. Assim, esses testes de vigor podem ser utilizados para uma seleção mais rigorosa dos lotes.

Ainda na Tabela 2, observa-se que os testes de emissão da raiz primária após 48, 72, 80 e 96 horas e de envelhecimento acelerado por 48 e 72 horas não foram tão eficientes na classificação dos lotes, quando comparados ao teste de referência adotado (de emergência em substrato) e ao conjunto dos demais testes. Verifica-se que o envelhecimento acelerado e a emissão da raiz primária após 48 horas não permitiram a diferenciação dos lotes 4 e 5 (respectivamente de médio e baixo vigor, segundo o teste de emergência de plântulas em substrato) ou mesmo entre esses e o lote 3, de alto vigor (emissão da raiz primária após 48 horas).

O teor de água inicial das sementes de todos os lotes estava muito próximo e, embora tenha ocorrido diferença significativa para essa característica entre os lotes, este fato parece ter influenciado apenas o teste da emissão da raiz primária, pois as sementes dos lotes 2 e 3 com menor teor de água $(5,2$ e $4,7 \%$, respectivamente), demoraram mais tempo para emitir a raiz primária que o lote 1 , que segundo os demais testes aplicados, possui vigor semelhante a esses lotes, mas com teor de água de 7,7\% (Tabelas 2 e 3). Assim, as sementes do lote 1 embora não diferissem em vigor dos lotes 2 e 3 , por estarem mais hidratadas iniciaram a emissão da raiz primária mais precocemente. Portanto, para maior eficiência esse teste deve ser aplicado a lotes de sementes com teores de água bastante próximos.

Sementes submetidas ao teste de envelhecimento acelerado modificado em solução salina absorveram quantidade de água bem menor do que àquelas submetidas ao teste normal, com água (Tabela 3). Os resultados obtidos na comparação de teste de envelhecimento acelerado com e sem sal, em 
TABELA 2. Resultados dos testes de germinação (G) e de vigor avaliado pelo teste de primeira contagem de germinação (PC), emissão de raiz primária (ER) após 48, 56, 72, 80 e 96 horas, emergência em substrato para mudas em substrato (EB), envelhecimento acelerado com sal (EAS) e sem sal (EAA) por 48 e 72 horas, condutividade elétrica (CE) 2, 4, 6, 8 e 24 horas de sementes de cinco lotes de couvebrócolos híbrido Flórida.

\begin{tabular}{|c|c|c|c|c|c|c|c|}
\hline \multirow{2}{*}{\multicolumn{2}{|c|}{ Testes de avaliação de qualidade }} & \multicolumn{5}{|c|}{ Lotes } & \multirow{2}{*}{$\mathrm{CV}(\%)$} \\
\hline & & 1 & 2 & 3 & 4 & 5 & \\
\hline \multicolumn{2}{|l|}{$\mathrm{E} \mathrm{B}(\%)$} & $81 \mathrm{a}$ & 89 a & $87 \mathrm{a}$ & $67 \mathrm{~b}$ & $17 \mathrm{c}$ & 4,92 \\
\hline \multicolumn{2}{|l|}{$\mathrm{G}(\%)$} & 89 a & $90 \mathrm{a}$ & 89 a & $83 \mathrm{a}$ & $38 \mathrm{~b}$ & 6,55 \\
\hline \multicolumn{2}{|l|}{$\mathrm{PC}(\%)$} & $60 \mathrm{a}$ & $48 \mathrm{ab} \ldots$ & $42 \mathrm{~b}$ & $6 c$ & $0 \mathrm{~d}$ & 10,88 \\
\hline \multirow{5}{*}{ ER $(\%)$} & 48 horas & $63 \mathrm{a}$ & $32 \mathrm{~b}$ & $4 \mathrm{c}$ & $3 \mathrm{c}$ & $0 \mathrm{c}$ & 19,12 \\
\hline & 56 horas & $68 \mathrm{a}$ & $35 \mathrm{~b}$ & $6 \mathrm{c}$ & $8 \mathrm{c}$ & $0 \mathrm{~d}$ & 12,27 \\
\hline & 72 horas & 77 a & $52 \mathrm{~b}$ & $22 \mathrm{c}$ & $37 \mathrm{~b}$ & $0 \mathrm{~d}$ & 10,15 \\
\hline & 80 horas & 86 a & $59 \mathrm{~b}$ & $31 \mathrm{c}$ & $65 \mathrm{~b}$ & $1 \mathrm{~d}$ & 6,79 \\
\hline & 96 horas & $92 \mathrm{a}$ & $74 \mathrm{~b}$ & $63 \mathrm{~b}$ & $68 \mathrm{~b}$ & $4 \mathrm{c}$ & 5,90 \\
\hline \multirow{2}{*}{ EAS (\%) } & 48 horas & $60 \mathrm{a}$ & $81 \mathrm{a}$ & $60 \mathrm{a}$ & $11 \mathrm{~b}$ & $0 \mathrm{c}$ & 10,68 \\
\hline & 72 horas & $68 \mathrm{ab}$ & $77 \mathrm{a}$ & $64 \mathrm{~b}$ & $8 \mathrm{c}$ & $0 \mathrm{~d}$ & 5,84 \\
\hline \multirow{2}{*}{ EAA $(\%)$} & 48 horas & 39 a & $51 \mathrm{a}$ & $51 \mathrm{a}$ & $1 \mathrm{~b}$ & $0 \mathrm{~b}$ & 13,50 \\
\hline & 72 horas & $33 \mathrm{~b}$ & $50 \mathrm{a}$ & $42 \mathrm{ab}$ & $0 \mathrm{c}$ & $0 \mathrm{c}$ & 9,99 \\
\hline CE & 2 horas & $174,75 \mathrm{~b}$ & $133,5 \mathrm{~b}$ & $142,25 \mathrm{~b}$ & $174,5 \mathrm{~b}$ & 249,75 a & 17,12 \\
\hline \multirow{4}{*}{$(\mu \mathrm{S} / \mathrm{cm} / \mathrm{g}$ semente $)$} & 4 horas & $206,50 \mathrm{~b}$ & $195,25 \mathrm{~b}$ & $200,00 \mathrm{~b}$ & $251,75 \mathrm{~b}$ & $382,50 \mathrm{a}$ & 16,28 \\
\hline & 6 horas & $252,25 \mathrm{~b}$ & $225,25 \mathrm{~b}$ & $235,75 \mathrm{~b}$ & $313,75 \mathrm{~b}$ & $477,00 \mathrm{a}$ & 14,09 \\
\hline & 8 horas & $283,50 \mathrm{bc}$ & $254,50 \mathrm{c}$ & $265,00 \mathrm{bc}$ & $354,25 \mathrm{~b}$ & 566,25 a & 13,08 \\
\hline & 24 horas & $380,25 \mathrm{bc}$ & $337,00 \mathrm{c}$ & $365,25 \mathrm{c}$ & $500,00 \mathrm{~b}$ & $842,50 \mathrm{a}$ & 11,53 \\
\hline
\end{tabular}

Médias seguidas pela mesma letra na linha não diferem entre si pelo teste de Tukey $(\mathrm{P}<0,05)$.

TABELA 3. Teor de água inicial e após o teste do envelhecimento acelerado com sal (EAS) e sem sal (EAA) por 48 e 72 horas em sementes de cinco lotes de couve-brócolos híbrido Flórida.

\begin{tabular}{|c|c|c|c|c|c|c|c|}
\hline \multirow{2}{*}{\multicolumn{2}{|c|}{ Teor de água (\%) }} & \multicolumn{5}{|c|}{ Lotes } & \multirow{2}{*}{$\mathrm{CV}(\%)$} \\
\hline & & 1 & 2 & 3 & 4 & 5 & \\
\hline \multicolumn{2}{|l|}{ Inicial } & $7,7 \mathrm{a}$ & $5,2 \mathrm{c}$ & $4,7 \mathrm{~d}$ & $7,0 \mathrm{~b}$ & $5,2 \mathrm{c}$ & 0,49 \\
\hline \multirow{2}{*}{ EAS } & 48 horas & $11,3 \mathrm{ab}$ & $10,3 \mathrm{~b}$ & $10,4 \mathrm{~b}$ & $12,5 \mathrm{a}$ & $11,3 \mathrm{ab}$ & 2,20 \\
\hline & 72 horas & $11,1 \mathrm{a}$ & $10,7 \mathrm{ab}$ & $9,8 \mathrm{c}$ & $10,2 \mathrm{~b}$ & $10,5 \mathrm{~b}$ & 0,63 \\
\hline \multirow{2}{*}{ EAA } & 48 horas & $44,1 \mathrm{a}$ & $39,7 \mathrm{~b}$ & $32,5 \mathrm{c}$ & $42,3 \mathrm{a}$ & $39,4 \mathrm{~b}$ & 0,93 \\
\hline & 72 horas & $46,3 \mathrm{~b}$ & $44,6 \mathrm{bc}$ & $42,4 \mathrm{c}$ & $46,0 \mathrm{~b}$ & $49,5 \mathrm{a}$ & 0,77 \\
\hline
\end{tabular}

Médias seguidas pela mesma letra na linha não diferem entre si pelo teste de Tukey $(\mathrm{P}<0,05)$.

cada tempo de exposição, mostraram que o envelhecimento com água (100\% UR) prejudicou mais a qualidade das sementes (Tabela 2). Dessa forma, pode-se verificar que a solução salina controlou a umidade relativa do ar (76\%UR), assim como a taxa de absorção de água da semente e conse- qüentemente, a velocidade e a intensidade de deterioração da mesma. De modo independente do teor de água atingido pelas sementes ao final do teste de envelhecimento acelerado com e sem solução salina, ambos testes mostraram-se eficientes na diferenciação dos lotes 5 e 4 dos demais. 


\section{CONCLUSÕES}

Os testes de primeira contagem de germinação, emissão da raiz primária após 56 horas e envelhecimento acelerado com solução saturada de sal $(\mathrm{NaCl})$ por 72 horas foram os mais sensíveis na diferenciação do vigor dos lotes, apresentando maior eficiência que a emergência de plântulas em substrato.

Os testes de envelhecimento acelerado com solução saturada de sal por 48 horas e condutividade elétrica após 8 e 24 horas de embebição também mostraram-se eficientes na avaliação do vigor das sementes de couve-brócolos, fornecendo informações equivalentes à emergência de plântulas em substrato.

\section{AGRADECIMENTOS}

A Sakata Seed Sudamerica LTDA nas pessoas de Carlos Alberto Rodrigues da Silva, Celso Netto e Evelyn Fernandes de Araújo Koch, pelo fornecimento das sementes utilizadas nesse trabalho.

\section{REFERÊNCIAS}

BRASIL. Ministério da Agricultura e da Reforma Agrária Regras para análise de sementes. Brasília: SNDA/DNDV/CLAV, 1992. $365 \mathrm{p}$.

DIAS, D.C.F.S.; VIEIRA, A.N.; BHÉRING, M.C. Condutividade elétrica e lixiviação de potássio para avaliação do vigor de sementes de hortaliças: feijão-de-vagem e quiabo. Revista Brasileira de Sementes, Brasília, v.20, n.2, p.408-413, 1998.

HAMPTON, J.G.; TEKRONY, D.M. Accelerated aging test. In: HANDBOOK of vigour tests methods. Zürich: International Seed Testing Association, 1995. p.1-10.

JIANHUA, Z.; McDONALD, M.B. The saturated salt accelerated aging test for small-seeded crops. Seed Science and Technology, Zürich, v.25, p.123-131, 1996.

KRZYZANOWSKI, F.C.; VIEIRA, R.D.; FRANÇA NETO, J.B. Vigor de sementes: conceitos e testes. Londrina: ABRATES, 1999.

MARCOS-FILHO, J. Teste de envelhecimento acelerado. In: KRZYZANOWSKI, F.C.; VIEIRA, R.D.; FRANÇA NETO, J.B. Vigor de sementes: conceitos e testes. Londrina: ABRATES, 1999. p.3.1-3.24.

MARCOS-FILHO, J.; SILVA, W.R.; NOVEMBRE, A.D.C.; CHAMMA, H.M.C.P. Estudo comparativo de métodos para avaliação da qualidade fisiológica de sementes de soja, com ênfase ao teste de condutividade elétrica. Pesquisa Agropecuária Brasileira, Brasília, v.25, n.12, p.1805-1815, 1990.
McDONALD, M.B.; WILSON, D.O. An assessment of the standardization of the ASA-610 to rapidly predict potential and soybean germination. Journal of Seed Techonology, Lincoln, v.4, n.1, p. 1-11, 1979.

MELLO, S.C.; SPÍNOLA, M.C.M.; MINAMI, K. Métodos de avaliação da qualidade fisiológica de sementes de brócolos. Scientia Agrícola, Piracicaba v.56, n.4, p.1151-1155, 1999.

NASCIMENTO, W.M.; BARROS, B.C.G.; PESSOA, H.B.S.V. Teste de envelhecimento acelerado em sementes de tomate. Revista Brasileira de Sementes, Brasília, v.15, n.2, p.251-253, 1993.

PANOBIANCO, M.; MARCOS-FILHO, J. Comparação entre métodos para avaliação da qualidade fisiológica de sementes de pimentão (Capsicum annuum L.) Revista Brasileira de Sementes, Brasília, v.20, n.2, p.306-310, 1998.

POWELL, A.A. Cell membranes seed leachate conductivity in relation to the quality of seed sowing. Journal of Seed Techonology, Lincoln, v.10, n.2, p.81-100, 1986.

RODO, A.B.; PANOBIANCO, M.; MARCOS-FILHO, J. Metodologia do envelhecimento acelerado para sementes de cenoura. In: CONGRESSO BRASILEIRO DE SEMENTES, 11., 1999, Foz do Iguaçu. Resumos... Foz do Iguaçu: ABRATES, 1999. p.131.

RODO, A.B.; TILLMANN, M.A.A.; VILLELA, F.A. Testes de vigor na avaliação da qualidade fisiológica de sementes de tomate. Revista Brasileira de Sementes, Brasília, v.20, n.1, p.23-28, 1998.

SÁ, M.E. Condutividade elétrica em sementes de tomate (Lycopersicum lycopersycum L.) Scientia Agrícola, Piracicaba v.56, n.1, p.13-20, 1999.

SALGADO, J.H.H. Avaliação do vigor de sementes de milho (Zea mays L.) pela precocidade de emissão da raíz primária. 1996. 86f. Tese (Doutorado) - Escola Superior de Agricultura "Luiz de Queiroz", Universidade de São Paulo, Piracicaba.

SIMON, E.W.; MATHAVAN, S. The time-course of leakage from imbibing seeds of different species. Seed Science and Technology, Zürich, v.14, n.1, p.9-13, 1986.

TEBALDI, N.D.; SADER, R.; BIRUEL, R.P.; SCALON, N.J.O.; BALLARIS, A.L.; GAVIOLI, E. Determinação do tempo e da temperatura para o teste de envelhecimento acelerado de sementes de couve-brócolos (Brassica oleracea L.) var. italica Plenk.. In: CONGRESSO BRASILEIRO DE SEMENTES, 11., Foz do Iguaçu, 1999. Resumos... Foz do Iguaçu: ABRATES, 1999. p. 120 .

TORRES, S.B.; MINAMI, K. Métodos para avaliar a qualidade fisiológica de sementes de pimentão (Capsicum annuum L.). In: CONGRESSO BRASILEIRO DE SEMENTES, 11., Foz do Iguaçu, 1999. Resumos. Foz do Iguaçu: ABRATES, 1999. p.127.

TORRES, S.B. Métodos para avaliação do potencial fisiológico de sementes de melão. 2002. 103f. Tese (Doutorado) - Escola Superior de Agricultura "Luiz de Queiroz", Universidade de São Paulo, Piracicaba.

VIEIRA, R.D.; CARVALHO, N.M. Testes de vigor em sementes. Jaboticabal: FUNEP, 1994. 164p. 